\title{
Optimization of Cutting Parameters Using Weighted Principal Component Analysis (WPCA) Combined with Grey Relational Analysis (GRA) While Turning of AA7075
}

\author{
Ch. Maheswara Rao ${ }^{1}$, K.Venkatasubbaiah ${ }^{2}$ and Ch. Suresh ${ }^{3}$ \\ ${ }^{1}$ (Assistant Professor, Department of Mechanical Engineering, Raghu Institute of \\ Technology, Visakhapatnam, India) \\ ${ }^{2}$ (Professor, Department of Mechanical Engineering, Andhra University, \\ Visakhapatnam, India) \\ Imahe.mech129@gmail.com,
}

\begin{abstract}
In the present work, an experimental study is made to optimize the cutting parameters for the multiple responses in CNC turning of AA7075 under dry environment using a tungsten carbide tool of $0.4 \mathrm{~mm}$ nose radius. The cutting speed, feed and depth of cut are selected as control factors at three different levels and Material Removal Rate (MRR) and Surface Roughness $\left(R_{a}\right)$ are considered as the experimental responses. The Multiple-responses are optimized using Weighted Principal Component Analysis (WPCA) combined with Grey Relational Analysis (GRA) and then the significance of the cutting parameters is determined by the Analysis of variance (ANOVA). The experiments are conducted as per the Taguchi's standard L9 (3^3) Orthogonal Array (OA). From the results, the optimal combination of cutting parameters for maximum Material Removal Rate and minimum Surface Roughness is obtained at: v3-f1-d3 i.e. cutting speed, 2000 RPM; feed, $0.2 \mathrm{~mm} / \mathrm{rev}$ and depth of cut, $1 \mathrm{~mm}$. ANOVA is applied at $95 \%$ of confidence level, i.e. $\alpha=0.05$ and the results revealed that feed is the most influencing parameter and followed by the depth of cut and cutting speed. The optimal design for the multiple responses is to be found in the range of 0.5839 to 0.9703 .
\end{abstract}

Keywords: Material Removal Rate (MRR), Surface Roughness $\left(R_{a}\right)$, AA7075, Weighted Principal Component Analysis (WPCA), Grey Relational Analysis (GRA), ANOVA

\section{Introduction}

The manufacturing industries are continuously challenged for manufacturing a product with low cost, high quality in less time. Productivity and quality are two conflicting objectives in any machining operations. Productivity can be increased by reduction in machining time, but it affects the quality. On the other hand, improvement of quality reduces the productivity as the machining time increases. [1-3] Therefore, it is a major task for the manufacturer to set the optimum machining variables in such a manner that the desired multiple objectives are to be achieved without sacrificing the profit. [4-5] Taguchi proposed a simple robust design to solve this problem. He proposed a design called an orthogonal array (OA) it covers all the parametric space with a less number of experiments. [6-8] Taguchi used a statistical measure of performance called Signal-to-Noise (S/N) ratio. The S/N ratio takes both the mean (Signal) and the variability (Noise) into account. The ratio depends on the quality characteristics of the product/process to be optimized. The standard $\mathrm{S} / \mathrm{N}$ ratios generally used are Higher the Better (HB), Lower the Better (LB), Nominal is Best (NB). The optimal setting is the parameter combination, which has the highest $\mathrm{S} / \mathrm{N}$ ratio. [9-10] The Taguchi method can be effectively used for single objective optimization problems, but in practical situations,

*Ch.Maheswara Rao 
optimizing a single response may yield positively in some aspects but it may affect adversely in other aspects. The problem can be overcome only if multiple objectives are optimized simultaneously. For optimizing the multiple objectives Taguchi based Grey relational analysis is proposed by Deng in 1982. [11-13] In Grey analysis, the experimental data are first normalized. Next, based on normalized data Grey relational coefficient is calculated to represent the correlation between the desired and actual experimental data. [14-15] then the overall Grey relational grade is determined by averaging the Grey relational coefficients of responses. The optimal parametric combination is then evaluated by maximizing the overall Grey relational grade. [16-17] the major drawback with Grey relational analysis of multi-objective optimization is that it assumes an equal importance to all the response variables therefore it assigns equal weights. [18-19] However, in real practice, the multiple response variables that are to be optimized do not carry equal weights. In order to define the individual weights to the multiple responses Principal component analysis (PCA) is implemented. [20-21] PCA, transforms the normalized response values into an uncorrelated linear combinations. After obtaining the linear combinations, the principal components can be formed. [22-24] In the application of PCA method, this selected component is regarded as an index in order to conveniently optimize the multi-response problem and to gain the best combination of factors/levels. [25-26] However, there are still two shortcomings in the PCA method. First, when more than one principal component is selected whose Eigen value is greater than 1; the required trade-off for a feasible solution is unknown. Second, the multi-response performance index cannot replace the multi-response solution when the chosen principal component can only be explained by total variation. [27-28] In order to overcome these two shortcomings in the PCA method, a weighted principal components analysis (WPCA) is used in the present work. [29-32] In WPCA method, all components are taken into consideration in order to completely explain variation in all responses.

The objective of the present work is to optimize the multiple responses in dry turning of AA7075 on a CNC turret lathe using a tungsten carbide tool. Aluminum alloys have a wide range of applications in manufacturing and aerospace industries. [33-35] a series of experiments are conducted as per the standard Taguchi's L9 orthogonal array. To optimize the multiple responses, Material Removal Rate (MRR) and Surface Roughness $\left(R_{a}\right)$ weighted principal component analysis (WPCA) along with Grey Relational Analysis (GRA) is employed. Taguchi method and Analysis of variance (ANOVA) are used to find the relative importance of cutting parameters on the multiple responses. [36-40] finally, the optimal design is predicted for the multi response i.e. Grey relational grade (GRG).

\section{Experimental Procedure}

\subsection{Experimental Setup}

The work specimens of AA7075 are taken for the experiments having each of size 60 $\mathrm{mm}$ in length and $30 \mathrm{~mm}$ diameter. The chemical composition and mechanical properties of AA7075 alloy are given in the Tables 1 and 2. The experiments are conducted on a CNC turret lathe (DX200, JOBBER XL) shown in the Figure 1 under dry environment. In the present work, the cutting parameters of speed, feed and depth of cut are considered as control factors and each parameter is designed at three different levels as given in the Table 3. Material removal rate and surface roughness are considered as response variables. 
Table 1. Chemical Composition of AA7075 Alloy

\begin{tabular}{|c|c|}
\hline Element & Weight (\%) \\
\hline Aluminium $(\mathrm{Al})$ & $87.1-91.4$ \\
\hline Zinc $(\mathrm{Zn})$ & $5.1-6.1$ \\
\hline Copper $(\mathrm{Cu})$ & $1.2-2.0$ \\
\hline Chromium $(\mathrm{Cr})$ & $0.18-0.28$ \\
\hline Iron $(\mathrm{Fe})$ & Max 0.5 \\
\hline Magnesium $(\mathrm{Mg})$ & $2.1-2.9$ \\
\hline Manganese $(\mathrm{Mn})$ & Max 0.3 \\
\hline Silicon $(\mathrm{Si})$ & Max 0.4 \\
\hline Titanium (Ti) & Max 0.2 \\
\hline Other & 0.05 \\
\hline
\end{tabular}

Table 2. Mechanical Properties of AA7075 Alloy

\begin{tabular}{|c|c|c|}
\hline Property & Value & Units \\
\hline Ultimate Tensile Strength & 572 & $\mathrm{MPa}$ \\
\hline Yield Strength & 503 & $\mathrm{MPa}$ \\
\hline Fatigue Strength & 159 & $\mathrm{MPa}$ \\
\hline Shear Strength & 331 & $\mathrm{MPa}$ \\
\hline \multirow{3}{*}{ Hardness } & 150 & $\mathrm{BHN}$ \\
\cline { 2 - 3 } & 53.5 & Rockwell A \\
\cline { 2 - 3 } & 87 & Rockwell B \\
\cline { 2 - 3 } & 175 & Vickers \\
\hline Density & 2.8 & $\mathrm{gm} / \mathrm{cm}^{3}$ \\
\hline Elongation & $3-9$ & $\%$ \\
\hline Modulus of Elasticity & 71.7 & $\mathrm{GPa}$ \\
\hline Poisson's Ratio & 0.33 & - \\
\hline Thermal Conductivity & 130 & $\mathrm{~W} / \mathrm{m}-\mathrm{K}$ \\
\hline Melting Point & $477-635$ & ${ }^{\circ} \mathrm{C}$ \\
\hline
\end{tabular}




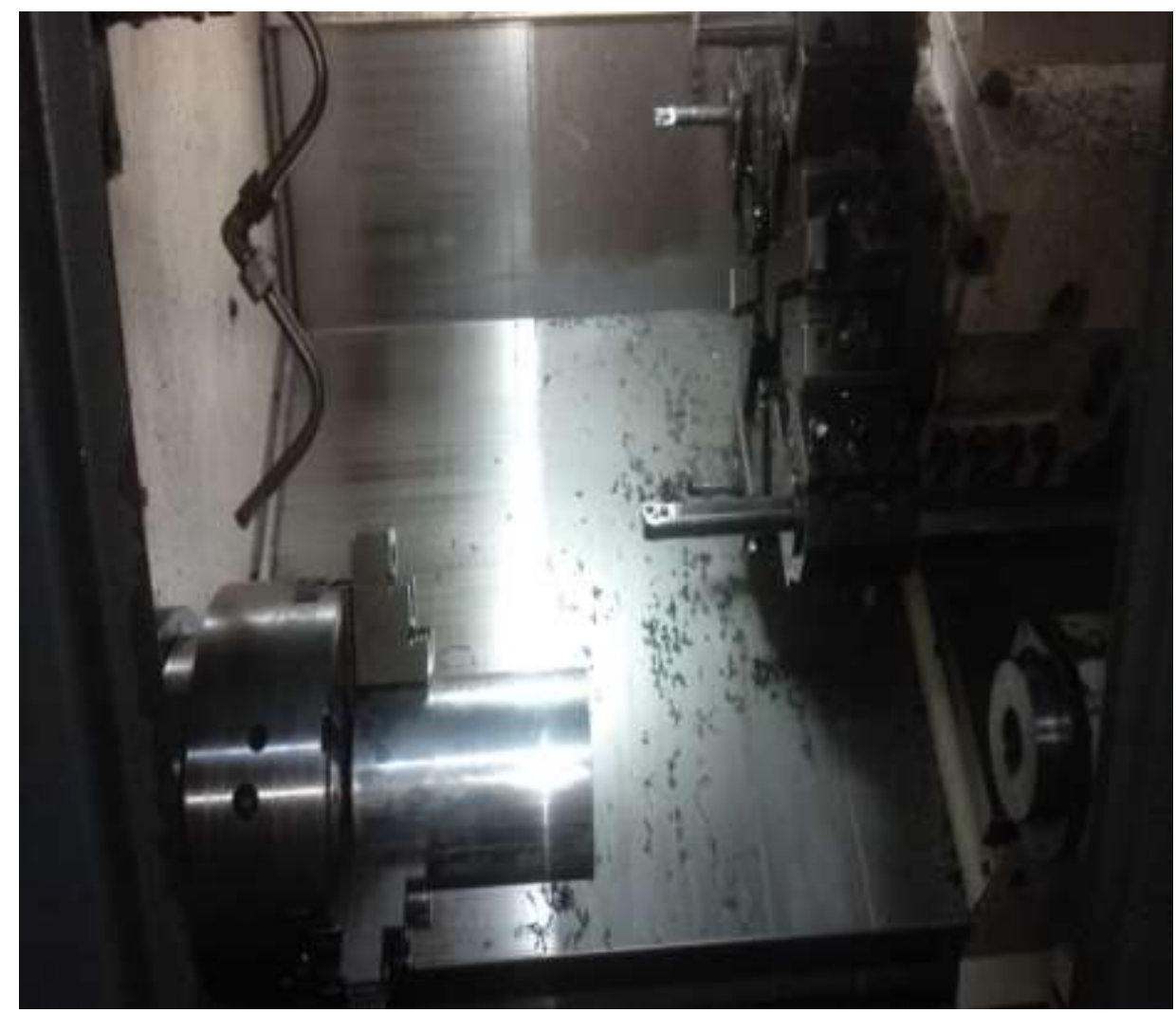

Figure 1. CNC Machine

Table 3. Cutting Parameters and their Levels

\begin{tabular}{|c|c|c|c|}
\hline $\begin{array}{c}\text { Levels in coded } \\
\text { form }\end{array}$ & \multicolumn{3}{|c|}{ Cutting parameters } \\
\cline { 2 - 4 } & $\begin{array}{c}\text { Spindle speed (N) } \\
(\mathrm{RPM})\end{array}$ & $\begin{array}{c}\text { Feed (f) } \\
(\mathrm{mm} / \mathrm{rev})\end{array}$ & $\begin{array}{c}\text { Depth of cut }(\mathrm{d}) \\
(\mathrm{mm})\end{array}$ \\
\hline-1 & 1000 & 0.2 & 0.5 \\
\hline 0 & 1500 & 0.3 & 0.75 \\
\hline 1 & 2000 & 0.4 & 1 \\
\hline
\end{tabular}

\subsection{Design of Experiments (DOE)}

Design of experiments (DOE) technique is used to obtain the maximum useful information from the minimum number of experimental runs. The selection of suitable Orthogonal array (OA) is an important task in Taguchi method. Orthogonal arrays are a special standard experimental design that requires a less number of experimental runs to find the main factor effects on output. The minimum number of experimental trails required in orthogonal array is given by $\mathrm{N}_{\min }=1+\mathrm{F}(\mathrm{L}-1)$. Where, $\mathrm{F}$ is the number of control factors $=3, \mathrm{~L}$ is the number of levels $=3, \mathrm{~N}_{\min }$ is the number of experiments to be conduct, $1+3(3-1)=7$. As per the Taguchi method, the orthogonal array selected must have equal to or more than seven runs. Based on this, L9 OA is selected and the factorial combination is given in the Table 4. 
Table 4. Standard Taguchi's L9 OA

\begin{tabular}{|c|c|c|c|}
\hline \multirow{2}{*}{ S.No. } & \multicolumn{3}{|c|}{ Factorial combination } \\
\cline { 2 - 4 } & $(\mathrm{N})$ & $(\mathrm{f})$ & $(\mathrm{d})$ \\
\hline 1 & -1 & -1 & -1 \\
\hline 2 & -1 & 0 & 0 \\
\hline 3 & -1 & 1 & 0 \\
\hline 4 & 0 & -1 & 1 \\
\hline 5 & 0 & 0 & -1 \\
\hline 6 & 0 & 1 & 1 \\
\hline 7 & 1 & -1 & -1 \\
\hline 8 & 1 & 0 & 0 \\
\hline 9 & 1 & 1 & \\
\hline
\end{tabular}

\section{Methodology}

The methodology employed in the present work involves in the following steps

- Identification of process parameters (Cutting speed, feed and depth of cut) and their levels (3 levels)

- Carryout the experiments as per the selected (L9) Orthogonal Array (OA)

- Measurement of quality characteristics (Material Removal Rate and Surface Roughness)

- Normalization of the quality characteristics

- Check for the correlation between the quality characteristics

- Finding out the Eigen values, Eigenvector and the corresponding principal components

- Finding out the individual Grey relational coefficient (GRC) values for quality characteristics

- Calculation of the overall Grey relational grade (GRG) value

- Ranking the experiments in the descending order of GRG values

\subsection{Calculation Procedure}

\section{Step 1: Get some experimental data}

Let $X_{i}(j)$ represents the response.

Where $\mathrm{i}=1,2 \ldots \mathrm{m}$; where $\mathrm{m}$ is the number of experiments performed.

$\mathrm{j}=1,2 \ldots \mathrm{n}$; where $\mathrm{n}$ is the number of quality characteristics.

\section{Step 2: Normalization of the quality characteristics}

Second step involves in the normalization of the experimental data according to Lower-the-Better (LB), Higher-the-Better (HB) and Nominal-the-Better (NB) characteristics given by the equations 1,2 and 3 respectively.

Lower-the-Better (LB)

$$
X_{i}^{s}(k)=\frac{\min x_{i}(k]}{x_{i}(k)}
$$

Higher-the-Better (HB)

$$
X_{i}^{s}(k)=\frac{X_{i}(k)}{\max X_{i}(k)}
$$

Nominal-the-Better (NB) 


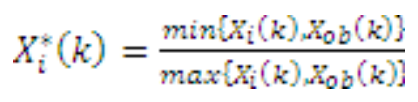

Here, $\mathrm{i}=1,2, \ldots \ldots \ldots, \mathrm{m}$;

$\mathrm{k}=1,2, \ldots \ldots, \mathrm{n}$

$\mathrm{X}_{\mathrm{i}}^{*}(\mathrm{k})$ is the normalized data of the $\mathrm{k}^{\text {th }}$ element in the $\mathrm{i}^{\text {th }}$ sequence.

$\mathrm{X}_{\mathrm{ob}}(\mathrm{k})$ is the desired value of the $\mathrm{k}^{\text {th }}$ quality characteristic.

\section{Step 3: check for correlation between the quality characteristics}

Third step is to check for the correlation between two quality characteristics using the equation 4.

$$
\rho_{j k}=\frac{\operatorname{Cov}\left[Q_{j} Q_{k}\right]}{\sigma_{Q_{j}} X Q_{Q_{k}}}
$$

Here, $\mathrm{j}=1,2, \ldots \ldots \ldots ., \mathrm{n}$
$\mathrm{k}=1,2, \ldots \ldots \ldots \ldots . \mathrm{n}$
$\mathrm{j} \neq \mathrm{k}$

Where, $\rho_{j k z}$ is the correlation coefficient between the quality characteristics

$\operatorname{Cov}\left(Q_{j}, Q_{k}\right)$ is the covariance of the quality characteristics

$\sigma_{Q_{j}}, \sigma_{Q_{K}}$ are the standard deviation of the quality characteristics

The correlation between the quality characteristics is checked by testing the following hypothesis

$$
\left\{\begin{array}{c}
H_{0}: \rho_{j k}=0 ; \text { there is no correlation } \\
H_{1}: \rho_{j k} \neq 0 ; \text { there is correlation }
\end{array}\right.
$$

\section{Step 4: Find out the Eigen values, Eigen vector and the corresponding principal} components

Fourth step involves in finding the Eigen values, Eigen vector and the corresponding principal components for the normalized data of quality characteristics.

The principal components of the quality characteristics can be obtain using the equation 5.

$$
Y_{i}(k)=\sum_{j=1}^{n} X_{i}^{8}(j) \beta_{k j,} i=0,1,2, \ldots, m ; k=1,2, \ldots \ldots, n
$$

Where, $Y_{i}(k)$ is the principal component of the $\mathrm{k}^{\text {th }}$ element in the $\mathrm{i}^{\text {th }}$ series

$X_{i}^{8}(j)$ is the normalized value of the $\mathrm{j}^{\text {th }}$ element in the $\mathrm{i}^{\text {th }}$ sequence and $\beta_{k j j}$ is the $\mathrm{j}^{\text {th }}$ element of Eigen vector $\beta_{k}$

\section{Step 5: Calculation of the quality loss $\left(\Delta_{0, i}(k)\right)$} 6.

The quality loss values of the principal components can be finding using the equation

$$
\begin{aligned}
& \Delta_{0, i}(k)= \\
& \left\{\begin{array}{c}
\left\|X_{0}^{8}(k)-X_{i}^{8}(k)\right\|_{\text {, no significant correlation between quality characteristics }} \\
\left\|Y_{0}(k)-Y_{i}(k)\right\|_{\text {, significant correlation between quality characteristics }}
\end{array}\right.
\end{aligned}
$$




\section{Step 6: Calculation of individual Grey Relational Coefficients}

The Grey coefficient values for the quality loss values of quality characteristics can be calculate by equation 7 .

$$
r_{0,1}(k)=\frac{\Delta_{\min }+\varepsilon \Delta_{\max }}{\Delta_{0, j}(k)+\varepsilon \Delta_{\max }}
$$

Where, $r_{0, i}(k)$ is the Grey relational coefficient value for individual quality characteristics

$\Delta_{Q_{0} i}(k)$ is the quality loss value and

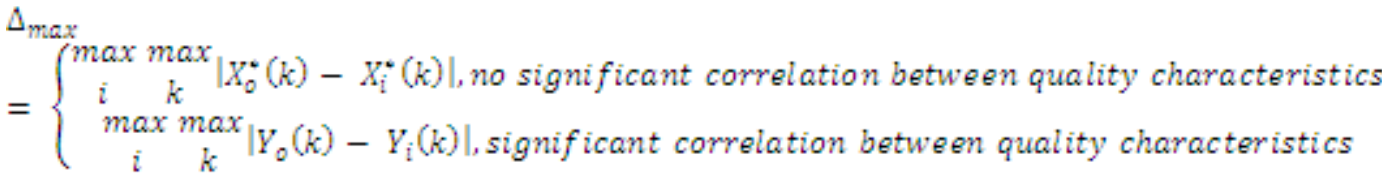

$$
\begin{aligned}
& \Delta_{\sin }= \\
& \int_{i} \min _{k} \mid X_{0}^{*}(k)-X_{i}^{*}(k) \|_{0} \text { no significant correlation between quality characteristics } \\
& \left\{\begin{array}{c}
\min _{i} \min \\
\left\|Y_{0}(k)-Y_{i}(k)\right\|_{s} \text { significant correlation between quality characteristics }
\end{array}\right.
\end{aligned}
$$

$\varepsilon_{\text {i }}$ is called the distinguishing coefficient, and its value lies in between 0 to 1 . In general for turning its value is 0.5 .

\section{Step 7: Calculation of overall Grey Relational Grade (GRG) value}

After finding the individual Grey coefficient values, the overall Grey relational grade value can be calculated by the equation 8 .

$$
\Gamma_{0_{0} i}=\sum_{k=1}^{n} w_{k} T_{0 i}(k), i=1,2, \ldots \ldots \ldots, m
$$

Where. $\Gamma_{O_{i}, \mathbb{1}}$ is overall Grey relational grade value.

$w_{k z}$ is the weight assigned or contribution of the individual quality characteristics.

$r_{O_{i} i}(k)$ is the Grey relational coefficient value of the individual quality characteristics.

\section{Step 8: Ranking in the descending order of overall Grey relational grade value}

\section{Results and Discussions}

The experimental results of material removal rate (MRR) and surface roughness $\left(R_{\mathrm{a}}\right)$ are given in the Table 5. The material removal rate is expressed as the ratio of weight difference of the work piece before and after machining to the machining time and is measured in $\mathrm{cm}^{3} / \mathrm{min}$ as given in the equation 9. The surface roughnesses are tested at three different points on each machined surface by Mitutoyo SJ-301 Surface tester and the average is taken as the final value.

$$
\text { Material Removal Rate }(\mathrm{MRR})=\frac{w_{\mathrm{i}}-w_{f}}{\rho_{\mathrm{f}}} \text { in } \mathrm{cm}^{3} / \mathrm{min}
$$

Where, $w_{i}=$ Initial weight of the work piece in grams

$\mathrm{w}_{\mathrm{f}}=$ Final weight of the work piece in grams

$\rho=$ density of the work material in $\mathrm{gm} / \mathrm{cm}^{3}$

$\mathrm{t}=$ machining time in minutes. 
Table 5. Experimental Results of Quality Characteristics

\begin{tabular}{|c|c|c|c|c|c|}
\hline S.No. & $\begin{array}{c}\mathrm{N} \\
(\mathrm{RPM})\end{array}$ & $\begin{array}{c}\mathrm{f} \\
(\mathrm{mm} / \mathrm{rev})\end{array}$ & $\begin{array}{c}\mathrm{d} \\
(\mathrm{mm})\end{array}$ & $\begin{array}{c}\mathrm{MRR} \\
\left(\mathrm{cm}^{3} / \mathrm{min}\right)\end{array}$ & $\begin{array}{c}\mathrm{R}_{\mathrm{a}} \\
(\mu \mathrm{m})\end{array}$ \\
\hline 1 & 1000 & 0.2 & 0.5 & 9.21 & 2.11 \\
\hline 2 & 1000 & 0.3 & 0.75 & 24.85 & 5.023 \\
\hline 3 & 1000 & 0.4 & 1 & 32.57 & 9.17 \\
\hline 4 & 1500 & 0.2 & 0.75 & 20.57 & 2.036 \\
\hline 5 & 1500 & 0.3 & 1 & 39.0 & 7.16 \\
\hline 6 & 1500 & 0.4 & 0.5 & 24.85 & 11.59 \\
\hline 7 & 2000 & 0.2 & 1 & 41.14 & 3.35 \\
\hline 8 & 2000 & 0.3 & 0.5 & 27.0 & 7.25 \\
\hline 9 & 2000 & 0.4 & 0.75 & 39.85 & 11.75 \\
\hline
\end{tabular}

The experimental results of Material removal rate and Surface roughness values are normalized using Lower-the-Better (LB) and Higher-the-Better (HB) characteristics given in the equations 1 and 2. The normalized values are given in the Table 6.

Table 6. Normalized Values of Quality Characteristics

\begin{tabular}{|c|c|c|}
\hline S.No. & MRR & $\mathrm{R}_{\mathrm{a}}$ \\
\hline 1 & 0.224 & 0.965 \\
\hline 2 & 0.604 & 0.405 \\
\hline 3 & 0.792 & 0.222 \\
\hline 4 & 0.5 & 1 \\
\hline 5 & 0.948 & 0.284 \\
\hline 6 & 0.604 & 0.176 \\
\hline 7 & 1 & 0.608 \\
\hline 8 & 0.656 & 0.281 \\
\hline 9 & 0.969 & 0.173 \\
\hline
\end{tabular}

The correlation between the quality characteristics are checked with the Pearson's correlation coefficient value. From the Table 7 it is found that a good correlation exists between the two quality characteristics.

Table 7. Correlation between the Quality Characteristics

\begin{tabular}{|c|c|c|c|}
\hline S.No. & Responses & $\begin{array}{c}\text { Pearson correlation } \\
\text { coefficient }\end{array}$ & Remarks \\
\hline 1 & MRR and $\mathrm{R}_{\mathrm{a}}$ & -0.610 & Both are correlated \\
\hline
\end{tabular}

For the normalized data, the Eigen values, Accountability proportion (AP) and Cumulative accountability proportion (CAP) values are calculated and given in the Table 8. Similarly, the Eigen vector of the normalized data is given in the Table 9. To obtain contribution of each of the response variable, Eigen vector values corresponding to the principal component is squared. The contributions of Material removal rate and surface roughness are given in the Table 10. 
Table 8. Eigen values, AP and CAP Values for Principal Components

\begin{tabular}{|c|c|c|}
\hline \multirow{2}{*}{ Eigen value } & PC1 & PC2 \\
\cline { 2 - 3 } & 1.6100 & 0.3900 \\
\hline $\begin{array}{c}\text { Accountability Proportion } \\
\text { (AP) }\end{array}$ & 0.805 & 0.195 \\
\hline $\begin{array}{c}\text { Cumulative Accountability } \\
\text { Proportion (CAP) }\end{array}$ & 0.805 & 1.000 \\
\hline
\end{tabular}

Table 9. Eigen Vector for Principal Components

\begin{tabular}{|c|c|c|}
\hline \multirow{2}{*}{$\begin{array}{c}\text { Quality } \\
\text { characteristic }\end{array}$} & $\begin{array}{c}\text { Primary principal } \\
\text { Component (PC1) }\end{array}$ & $\begin{array}{c}\text { Secondary principal } \\
\text { component (PC2) }\end{array}$ \\
\cline { 2 - 3 } & 0.707 & -0.707 \\
\hline MRR & -0.707 & -0.707 \\
\hline $\mathrm{R}_{\mathrm{a}}$ &
\end{tabular}

Table 10. Contribution of Individual Quality Characteristics for Principal Components

\begin{tabular}{|c|c|}
\hline Quality characteristic & Contribution \\
\hline MRR & 0.5 \\
\hline $\mathrm{R}_{\mathrm{a}}$ & 0.5 \\
\hline
\end{tabular}

From the normalized data and Eigen vector matrices the Major principal components are calculated using the equation 5. The Principal components for the normalized quality characteristics obtained are given in the Table 11.

Table 11. Major Principal Components

\begin{tabular}{|c|c|c|}
\hline S.No. & MRR & $\mathrm{R}_{\mathrm{a}}$ \\
\hline Ideal & 0 & -1.414 \\
\hline 1 & -0.5239 & -0.8405 \\
\hline 2 & 0.1405 & -0.7136 \\
\hline 3 & 0.4028 & -0.7167 \\
\hline 4 & -0.3535 & -1.0605 \\
\hline 5 & 0.4692 & -0.8713 \\
\hline 6 & 0.3028 & -0.5512 \\
\hline 7 & 0.2773 & -1.1367 \\
\hline 8 & 0.2655 & -0.6625 \\
\hline 9 & 0.5623 & -0.8073 \\
\hline
\end{tabular}

The quality loss values of principal components are calculated by the equation 6 and given in the Table 12.

Table 12. Quality Loss Values of Principal Components

\begin{tabular}{|c|c|c|}
\hline S.No. & MRR & $\mathrm{R}_{\mathrm{a}}$ \\
\hline 1 & 0.5239 & 0.5735 \\
\hline 2 & 0.1405 & 0.7004 \\
\hline 3 & 0.4028 & 0.6973 \\
\hline 4 & 0.3535 & 0.3535 \\
\hline 5 & 0.4692 & 0.5427 \\
\hline
\end{tabular}




\begin{tabular}{|l|l|l|}
\hline 6 & 0.3028 & 0.8628 \\
\hline 7 & 0.2773 & 0.2773 \\
\hline 8 & 0.2655 & 0.7515 \\
\hline 9 & 0.5623 & 0.6067 \\
\hline
\end{tabular}

After calculation of quality loss values, the individual Grey relational coefficient values are calculated by the equation 7 and given in the Table 13 .

Table 13. Grey Relational Coefficient (GRC) Values

\begin{tabular}{|c|c|c|}
\hline S.No. & MRR & $\mathrm{R}_{\mathrm{a}}$ \\
\hline 1 & 0.5238 & 0.7052 \\
\hline 2 & 1.0000 & 0.6262 \\
\hline 3 & 0.6165 & 0.6279 \\
\hline 4 & 0.6644 & 0.9029 \\
\hline 5 & 0.5619 & 0.7275 \\
\hline 6 & 0.7221 & 0.5476 \\
\hline 7 & 0.7550 & 1.0000 \\
\hline 8 & 0.7713 & 0.5991 \\
\hline 9 & 0.4999 & 0.6827 \\
\hline
\end{tabular}

For the individual Grey relational coefficient values, the overall Grey relational grade values are found by the equation 8 and the corresponding $\mathrm{S} / \mathrm{N}$ ratios are given in the table 14. The Signal-to-Noise ratios for the Grey relational grade values are obtained using the Higher-the-Better characteristic given in the equation 10. Finally, The ranking is given in the descending order of $\mathrm{S} / \mathrm{N}$ ratios of $\mathrm{GRG}$.

Higher-the-Better $(\mathrm{HB}): \frac{S}{N}=-10 \log _{10}\left[\frac{1}{Y_{i}^{2}}\right]$

Where, $Y_{i}$ is response value.

Table 14. Grey Relational Grade (GRG) and Signal-to-Noise (S/N) Ratios of GRG

\begin{tabular}{|c|c|c|c|}
\hline S.No. & GRG & S/N of GRG & Rank \\
\hline 1 & 0.6145 & -4.2295 & 8 \\
\hline 2 & 0.8131 & -1.7972 & 2 \\
\hline 3 & 0.6222 & -4.1214 & 7 \\
\hline 4 & 0.7836 & -2.1175 & 3 \\
\hline 5 & 0.6447 & -3.8123 & 5 \\
\hline 6 & 0.6348 & -3.9468 & 6 \\
\hline 7 & 0.8775 & -1.1348 & 1 \\
\hline 8 & 0.6852 & -3.2833 & 4 \\
\hline 9 & 0.5913 & -4.5638 & 9 \\
\hline
\end{tabular}




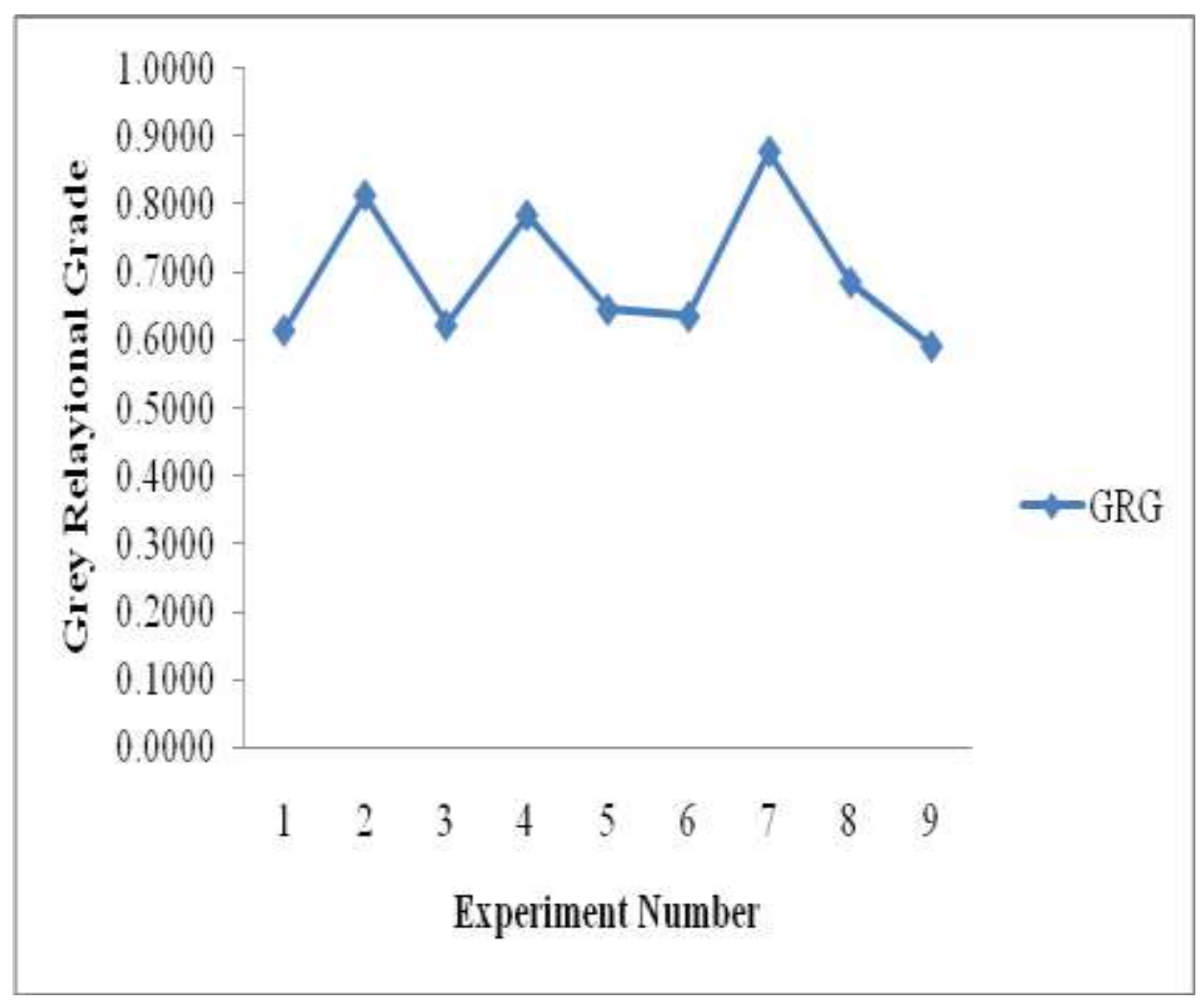

Figure 2. Experiment Number (Vs.) Grey Relational Grade

The Figure 2 shows, the variation of the Grey relational grade value with the experiment number. From the figure, it is observed that the higher GRG value is found in the seventh experiment. Hence, the optimum combination of cutting parameters for the multiple responses is found at: v3-f1-d3, values are given in the Table 15.

Table 15. Optimal Combination of Cutting Parameters

\begin{tabular}{|c|c|c|}
\hline Cutting parameter & Level & Value \\
\hline Speed (N) & 3 & $2000 \mathrm{RPM}$ \\
\hline Feed (f) & 1 & $0.2 \mathrm{~mm} / \mathrm{rev}$ \\
\hline Depth of cut (d) & 3 & $1 \mathrm{~mm}$ \\
\hline
\end{tabular}

Taguchi method is employed for the analysis of Grey relational grade value obtained and the results are given in the Table 16. From the results, it is observed that the feed is the dominant parameter in affecting the multiple responses and followed by the depth of cut and cutting speed.

Table 16. Response Table for Means of GRG

\begin{tabular}{|c|c|c|c|}
\hline Level & $\mathrm{N}$ & $\mathrm{f}$ & $\mathrm{d}$ \\
\hline 1 & 0.6833 & 0.7586 & 0.6449 \\
\hline 2 & 0.6877 & 0.7144 & 0.7293 \\
\hline 3 & 0.7180 & 0.6161 & 0.7148 \\
\hline Delta (Max-Min) & 0.0348 & 0.1424 & 0.0845 \\
\hline Rank & 3 & 1 & 2 \\
\hline
\end{tabular}

Analysis of Variance (ANOVA) is used to find the influence of cutting parameters on the multiple responses. ANOVA is applied at a confidence level of 95\%, i.e. $\alpha=0.05$. From F-test values shown in Table 17, it is clear that the feed is the most influencing 
parameter on the multiple responses. The Normality of the residuals is checked by the Normal probability plot which is shown in the Figure 3.

Table 17. Analysis of Variance (ANOVA) for GRG

\begin{tabular}{|c|c|c|c|c|c|}
\hline Source & DF & Seq SS & Adj SS & Adj MS & F \\
\hline N & 2 & 0.00214 & 0.00214 & 0.00107 & 0.06 \\
\hline f & 2 & 0.03190 & 0.03190 & 0.01595 & 0.85 \\
\hline d & 2 & 0.01225 & 0.01225 & 0.00612 & 0.33 \\
\hline Error & 2 & 0.03759 & 0.03759 & 0.01879 & \\
\hline Total & 8 & 0.08388 & & & \\
\hline
\end{tabular}

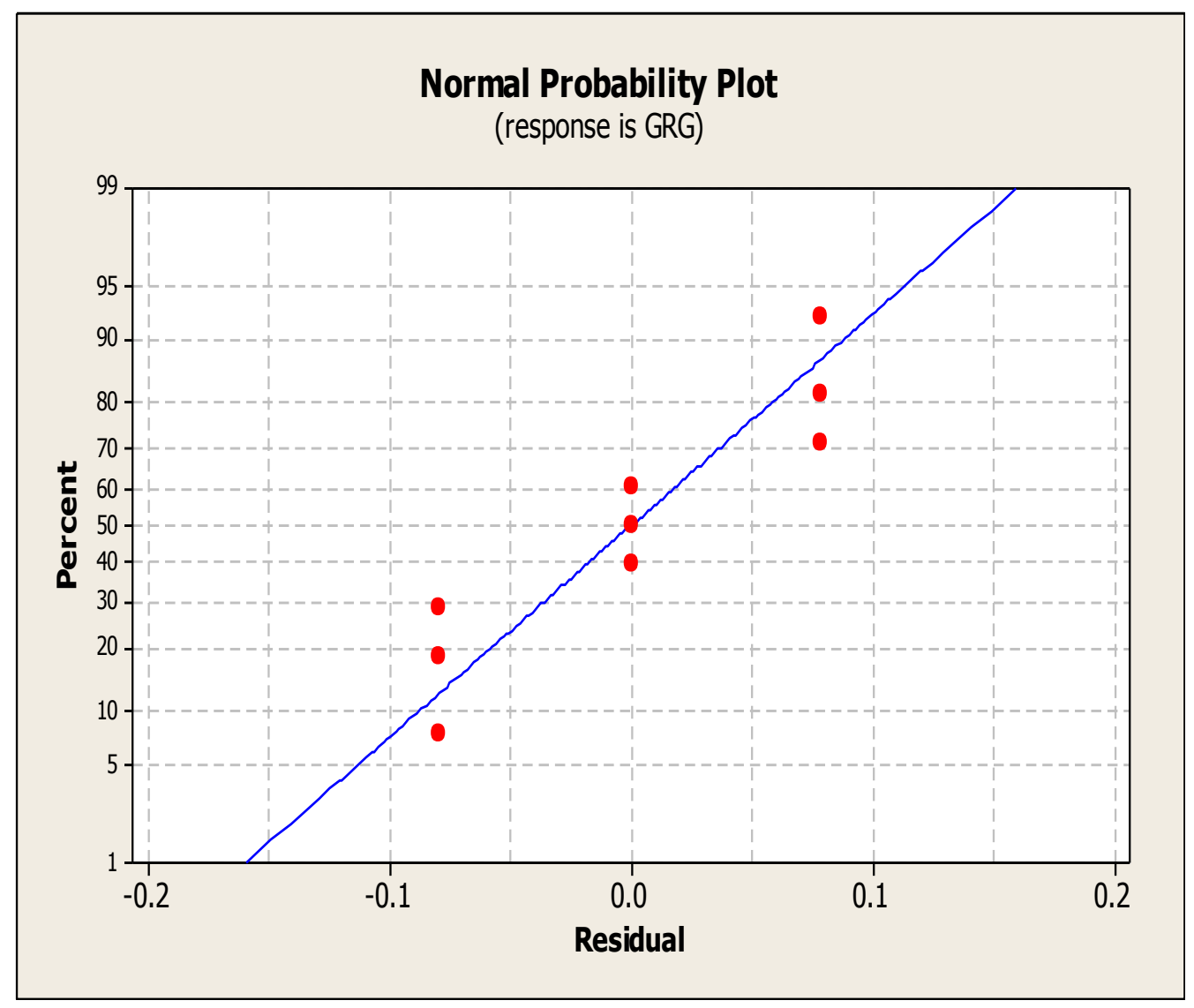

Figure 3. Normal Probability Plot of GRG

\subsection{Prediction of Optimal Design for GRG}

The optimal design for the Grey relational grade (GRG) values can be found out based on the estimated average by considering two most significant factors are taken at their best levels. In the present work Feed and depth of cut are the two most significant factors at first and high levels respectively.

$\mu_{A 1 B 3}=A_{1}+B_{3}-T$

Where, $A_{1}=0.7586 ; B_{3}=0.7148$ (From Table 16)

and $\mathrm{T}=0.6963$ (From Table 14)

$\mu_{A 1 B 3}=A_{1}+B_{3}-T$

$\mu_{A 1 B 3}=0.7586+0.7148-0.6963=0.7771$ 
$C I=\sqrt{\frac{F_{959,1} \text { idoferror } * V_{\text {error }}}{\eta_{\text {ef ficiency }}}}$

Where, $\eta_{\text {efficiency }}=\frac{W}{[1+d \text { dof }]}$

$\mathrm{N}=$ Total number of experiments $=9$

$\mathrm{DOF}=$ Degree of freedom for two significant factors $=4$

$\eta_{\text {efficiency }}=\frac{9}{(1+2+2)}=1.8$

$V_{\text {error }}=0.01879$ (From Table 17)

$\mathrm{F}_{95 \%, 1,2}=18.5128$ (From standard F-Table)

$C I=\sqrt{\frac{(18.5128 * 0.01879)}{1.8}}$

$C I=0.1932$

The predicted optimal range of GRG at $95 \%$ confidence level is obtained as

$\mu_{A 1 B 3}-C I \leq \mu_{A 1 B 3} \leq \mu_{A 1 B 3}+C I$

$0.7771-0.1932 \leq \mu_{A 1 B 3} \leq 0.7771+0.1932$

$0.5839 \leq \mu_{\text {A1B3 }} \leq 0.9703$

\section{Conclusions}

- The optimal combination of cutting parameters to achieve a high material removal rate and low surface roughness is obtained at v3-f1-d3.

Cutting speed: level 3, 2000 RPM

Feed: level 1, $0.2 \mathrm{~mm} / \mathrm{rev}$

Depth of cut: level 3, $1 \mathrm{~mm}$

- Feed is the most dominant factor in affecting the multiple responses followed by the depth of cut and speed.

- ANOVA results of Grey relational grade reveal that the errors of residuals are following normal distribution.

- The optimal design for Grey relational grade is to be found in the range of 0.5839 to 0.9703 .

- The weighted principal component analysis (WPCA) combined with Grey analysis (GRA) is very effective and efficient method for the optimization of multiple responses.

\section{References}

[1] H.K. Dave, L.S. Patel and H.K. Raval, "Effect of Machining Conditions on MRR and Surface Roughness During CNC Turning of Different Materials Using TiN Coated Cutting Tools by Taguchi Method", International Journal of Industrial Engineering Computations, vol.3, (2012), pp. 925-930.

[2] R. Gupta and A. Diwedi, "Optimization of Surface Finish and Material Removal Rate with Different Insert Nose Radius for Turning Operation on CNC Turing Centre", International Journal of Innovative Research in Science, Engineering and Technology, vol.3, no.6, (2014), pp. 13540-13547.

[3] M. Kaladhar, K. Venkata Subbaiah and Ch. Srinivasa Rao, "Parametric Optimization During Machining of AISI 304 Austenitic Stainless Steel Using CVD Coated DURATOMIC Cutting Insert", International Journal of Industrial Engineering Computations, vol.3, (2012), pp. 577-586.

[4] H. Kumar, M. Abbas, A. Mohammad and H. Zakir Jafri, "Optimization of Cutting Parameters in CNC Turning", International Journal of Engineering Research and Applications, vol.3, no.3, (2013), pp. 331-334.

[5] K. Pavan Kumar Reddy, Y. Rameswara Reddy and R. Vishnuvardhan Reddy, "Optimization of Surface Roughness and MRR in Turning Operation Using Extended Taguchi Method", International Journal of Engineering Research, vol.3, no.1, (2014), pp. 92-96.

[6] H.K. Vijaya Kumar, S. Aboobaker and S. Muhammed, "Optimization of Turning Parameters Using Taguchi Technique for MRR and Surface Roughness of Hardened AISI 52100 Steel”, International Journal of Engineering Research and Applications, vol.4, no.5,(6), (2014), pp. 39-44.

[7] S. Thamizhmanii, S. Saparudin and S. Hasan, "Analysis of Surface Roughness by Turning Process 
Using Taguchi Method", Journal of Achievements in Materials and Manufacturing, vol. 20, no. 1-2, (2007), pp. 503-506.

[8] H. Singh and P. Kumar, "Optimizing Feed Force for Turned Parts Through the Taguchi Technique", Sadana, vol.31, no. 6, (2006), pp. 671-681.

[9] G. Shivam, K. Varanpal Singh and Prakhar Yadav, "Experimental Study of Turning Operation and Optimization of MRR and Surface Roughness Using Taguchi Method", International Journal of Innovative Research in Advanced Engineering, vol.3, 3, (2016), pp. 44-50.

[10] D. Selvaraj and P. Chandramohan, "Optimization of Surface Roughness of AISI304 Austenitic Stainless Steel in Dry Turning Operation Using Taguchi Design Method", Journal of Engineering Science and Technology, vol. 5, no. 3, (2010), pp.293-301.

[11] S.S. Mahapatra and A. Patnaik, "Optimization of Wire Electrical Discharge Machining (WEDM) Process Parameters Using Taguchi Method", International Journal of Advanced Manufacturing Technology, Vol. 34, (2007), pp. 911-925.

[12] D. Chakadhar and A. Venu Gopal, "Multi Objective Optimization of Electro Chemical Machining of EN31 Steel by Grey Relational Analysis", International Journal of Modeling and Optimization, vol.1, (2011), pp.113-117.

[13] J. Kamal, S. Grover and A. Aggarwal, "Simultaneous Optimization of Material Removal Rate and Surface Roughness for WEDM of WCCo Composite Using Grey Relational Analysis Along With Taguchi Method", International Journal of Industrial Engineering Computations, vol.2, (2011), pp. 479-490.

[14] A. Vikas, Kumar Roy and K. Kumar, "Effect and Optimization of Machine Process Parameters on Material Removal Rate in EDM for EN41 Material Using Taguchi”, International Journal of Mechanical Engineering and Computer Applications, vol. 1, Issue 5, (2013), pp. 35-39.

[15] M. Tiwari, K. Mausam, K. Sharma and R. Pratap Singh, "Investigate the Optimal Combination of Process Parameters for EDM by Using a Grey Relational Analysis", Elsvier journal, Procedia Material Science, vol. 5, (2014), pp. 1736-1744.

[16] Ch. Maheswara Rao, K. Venkatasubbaiah and K. Jagadeeswara Rao, "Experimental Investigation of Surface Roughness Characteristics $\mathrm{R}_{\mathrm{a}}, \mathrm{R}_{\mathrm{q}}$ and $\mathrm{R}_{\mathrm{z}}$ ”, International Journal of Hybrid Information Technology, vol.9, no.7, (2016), pp.373-388.

[17] D. Chakadhar and A. Venu Gopal, "Multi Objective Optimization of Electro Chemical Machining of EN31 Steel by Grey Relational Analysis", International Journal of Modelling and Optimization, vol.1, (2011), pp.113-117.

[18] D. Kanta Das, A. Kumar Sahoo, R. Das and B.C. Routara "Investigations on Hard Turning Using Coated Carbide Insert: Grey based Taguchi and Regression Methodology", Elsvier Journal, Procedia Material Science, vol. 6, (2014), pp. 1351-1358.

[19] J.T. Huang and J.L. Lin, "Optimization of Machining Parameters Setting of EDM Process Based on Grey Relational Analysis with L18 Orthogonal Array", Journal of technology, vol. 17, (2002), pp. 659-664.

[20] M. Patel and I. Pramod, "Optimization of CNC TC Process Parameters Using PCA-based Taguchi Method", International Journal of Innovative Research in Science, Engineering and Technology, vol.5, issue 4, (2016), pp. 4722-4731.

[21] B. Venugopal, R. Ramachandra and B. Sreenivasulu, "Experimental Investigation and Optimization of Process Parameters in Plasma Arc Cutting Process", International Journal of Engineering Science and Computing, vol.6, issue 8, (2016), pp.2146-2151.

[22] R. Sethy, C.K. Biswas and S. Dewangan, "Multi Response Optimization for Correlated Responses in EDM Using Principal Component Analysis", Advanced Materials Manufacturing \& Characterization, vol.3, issue 1, (2013), pp. 207-210.

[23] C. Kayastha and Jaivesh Gandhi, "Optimization of Process Parameter in Turning of Copper by Combination of Taguchi and Principal Component Analysis Method", International Journal of Scientific and Research Publications, vol.3, issue 6, (2013), pp.1-6.

[24] H.S. lu, C.K. Chang, N.C. Hawang and C.T. Chung, "Grey Relational Analysis Coupled with Principal Component Analysis for Optimization Design of the Cutting Parameters in High Speed End Milling”, Journal of Material Processing Technology, (2009), pp. 3808-3817.

[25] Sk. Mahaboob Johny, Ch. Ramya sri sai, V. Ramakrishna rao and B. Govind singh, "Multi-Response Optimization of Aluminum Alloy Using GRA \& PCA by Employing Taguchi Method", International Research Journal of Engineering and Technology, vol.3, issue 1, (2016), pp.680-686.

[26] P. Ananthakumar, M. Ramesh and Parameshwari, "Optimization of Turning Process Parameters Using Multivariate Statistical Method-PCA Coupled with Taguchi Method”, International Journal of Scientific Engineering and Technology, vol.2, issue 4, (2013), pp. 263-267.

[27] M. Sanjit, D. Saurav, B. Asish and P. Pradip Kumar, "Optimization of CNC End Milling Process Parameters Using PCA-Based Taguchi Method", International Journal of Engineering, Science and Technology, vol.2, no.1, (2010), pp. 92-102.

[28] Suha K. Shihab, Zahid A. Khan and Arshad Noor Siddiquee, "Application of Grey Relational Analysis Along With Principal Component Analysis for Multi-Response Optimization of Hard Turning", International Journal of Engineering Trends and Technology, vol.38, no.5, (2016), pp.238-245. 
[29] M.K. Das, K. Kumar, T.K. Barman and P. Sahoo, "Optimization of MRR and Surface Roughness in PAC of EN31 Steel Using Weighted Principal Component Analysis", Procedia Technology 14, $2^{\text {nd }}$ International Conference on Innovations in Automation and Mechatronics Engineering, (2014), pp.211-218.

[30] M.K. Pradhan, M. Meena, Shubham Sen and Arvind Singh, "Multi-Objective Optimization in End Milling of Al-6061 Using Taguchi Based G-PCA", International Journal of Mechanical, Aerospace, Mechatronic and Manufacturing Engineering, vol.9, no.6, (2015), pp. 1136-1142.

[31] G.K. Singh, N.K. Chauhan, Rajeev Kumar and V. Yadava, "Grey Relational Analysis Coupled with Principal Component Analysis for Optimization Design of the Machining Parameters in Electro-Discharge Diamond Face Grinding”, International Journal of Current Engineering and Technology, issue.2, (2014), pp. 23-27.

[32] Rajesh Kumar, M.K. Pradhan and Rishi Kumar, "Modeling and Optimization of End Milling Parameters on Aluminum 6061 Alloy Using GRA Based Taguchi Method Coupled with PCA", Proceedings of the $5^{\text {th }}$ International \& $26^{\text {th }}$ All India Manufacturing Technology, Design and Research Conference, IIT Guwahati, Assam, India, (2014).

[33] M.S. Ranganath, Vipin, R.S. Mishra, Prateek and Nikhil, "Optimization of Surface Roughness in CNC Turning of Aluminium 6061 Using Taguchi Techniques", International Journal of Modern Engineering Research, vol.5, issue 5, (2015), pp.42-50.

[34] M. S. Ranganath, Vipin, Nand Kumar and Rakesh Kumar, "Experimental Analysis of Surface Roughness in CNC Turning of Aluminium Using Response Surface Methodology", International Journal of Advance Research and Innovation, vol. 3, issue 1, (2015), pp. 45-49.

[35] M. S. Ranganath, Vipin and R. S. Mishra, "Optimization of Surface Roughness and Material Removal Rate on Conventional Dry Turning of Aluminium (6061)", International Journal of Advance Research and Innovation, vol. 1, (2014), pp. 62-71.

[36] M. Kaladhar, K.V. Subbaiah and C. Srinivasa Rao, "Determination of Optimal Process Parameters During Turning of AISI304 Austenitic Stainless Steel using Taguchi method and ANOVA", International Journal of Lean Thinking, vol.3, no. 1, (2012).

[37] M.Gopalaswamy, B. Mondal and S. Ghosh, "Taguchi Method and ANOVA: An Approach for Process Parameters Optimization of Hard Machining While Machining Hardened Steel”, Journal of Scientific and Industrial Research, vol. 68, (2009), pp. 686-695.

[38] M. Kaladhar, K. VenkataSubbaiah, Ch. Srinivasa Rao and K. Narayana Rao, "Optimization of Process Parameters in Turning of AISI202 Austenitic Stainless Steel”, ARPN Journal of Engineering and Applied Sciences, Vol. 5, No. 9, (2010), pp. 79-87.

[39] Ch. Maheswara Rao and K. Venkatasubbaiah, "Optimization of Surface Roughness in CNC Turning Using Taguchi Method and ANOVA”, International Journal of Advanced Science and Technology, vol.93, (2016), pp.1-14.

[40] Ch. Maheswara Rao and K. Venkatasubbaiah, "Effect and Optimization of EDM Process Parameters on Surface Roughness for EN41 Steel”, International Journal of Hybrid Information Technology, vol.9, no.5, (2016), pp. 343-358. 
International Journal of Hybrid Information Technology

Vol. 10, No.1 (2017) 